\title{
PARA ALÉM DE UMA DEMOCRACIA DE ESPECTADORES*
}

\author{
Marcelo Pereira**
}

MÁS ALLÁ DE UNA DEMOCRACIA DE ESPECTADORES

BEYOND A DEMOCRACY OF SPECTATORS

Data de recepção: 25 de abril de 2016.

Data de aprovação: 20 de junho de 2016.

\section{Sugerencia de citación:}

Pereira, M. (2016). Para além de uma democracia de espectadores. Razón Crítica, 1, 148-169, doi: http://dx.doi.org/10.21789/25007807.1140

* O presente ensaio se estruturou a partir de um trabalho desenvolvido no Programa de Doutorado em Sociologia, na disciplina Teorias Sociológicas Avançadas, do programa de Doutoramento em Sociologia, da Faculdade de Economia, na Universidade de Coimbra -Portugal-, sob a orientação do Prof. Dr. Carlos Fortuna, do Prof. Dr. João Arriscado Nunes e do Prof. Dr. José Manoel Mendes.

** Advogado. Mestre em Direito de Estado pela Universidade da Amazônia - Unama. Doutorando em Sociologia pela Faculdade de Economia, Universidade de Coimbra. Professor de Ciência Política e Direito Constitucional pela Estácio/FCAT - Faculdades Integradas de Castanhal. Ex-Presidente da Ordem dos Advogados do Brasil - Subseção Castanhal/PA (Brasil). Correio eletrônico: marcelopereira1205@gmail.com. 


\section{RESUMO}

O presente ensaio é uma reflexão sobre a noção do espirito do novo capitalismo, a partir de descrição feita por Richard Sennett, em sua obra A cultura do novo capitalismo, e identificar de que modo esse conceito impacta na compreensão dos desafios à democracia no século XXI, notadamente na construção de uma percepção emancipatória lastreada em um discurso argumentativo que agregue em si o estimulo à participação consciente dos indivíduos a outras formas de manifestações democráticas para além da representativa.

PALAVRAS-CHAVE:

democracia, capitalismo, cidadania, participação, emancipação. 


\section{RESUMEN}

Este ensayo es una reflexión sobre la noción de espíritu del nuevo capitalismo, a partir de la descripción hecha por Richard Sennett en su libro La cultura del nuevo capitalismo, e identifica cómo este concepto tiene impacto en la comprensión de los desafíos de la democracia en el siglo XXI, sobre todo en la construcción de una percepción emancipatoria respaldada por un discurso argumentativo que incluya en sí el estímulo a la participación consciente de los individuos en otras formas de manifestaciones democráticas más allá de la representativa..

PALABRAS CLAVE:

democracia, capitalismo, ciudadanía, participación, emancipación. 


\begin{abstract}
This essay is a reflection on the concept of spirit of the new capitalism, starting from the description by Richard Sennett in his book The culture of the new capitalism, and identifies how this concept have impact on the understanding of the challenges of democracy in the twenty-first century, notably in the construction of an emancipatory perception backed by an argumentative discourse that lends on itself the impulse to the conscious participation of individuals into other forms of democratic manifestations beyond the representative.
\end{abstract}

KEYWORDS:

democracy, capitalism, citizenship, participation, emancipation. 


\section{N T R O D U Ç Ã O}

A democracia está doente de seu descomedimento: a liberdade torna-se tirania, o povo se transforma em massa manipulável, o desejo de promover o progresso se converte em espírito de cruzada. A economia, o Estado e o direito deixam de ser meios destinados ao florescimento de todos e participam apenas de um processo de desumanização. [...]

Viver numa democracia continua sendo preferível à submissão a um Estado totalitário, a uma ditadura militar ou a um regime feudal obscurantista. Mas, corroída assim

por seus inimigos íntimos, engendrados por ela mesma, a democracia já não está à altura de suas promessas.

Todorov, 2012, p. 197.

1. John Dunn registra que "ninguém, por conseguinte, sabe realmente o que a população mundial entende por democracia" (2014, p. 189). Entretanto, mesmo diante desse insuperável desafio, "[...] ao longo do tempo, cientistas políticos têm feito tentativas de descobrir isso, com graus variados de rigor e perspicácia, tanto em países específicos quanto em perspectivas mais amplas" (Dunn, 2014, p. 189).
A imagem de democracia não se reduz a um conceito unívoco, e muito menos a um juízo definitivo. Antes se define como uma ideia de tessitura flexível, percebida sob o espectro de cada época e como experiência histórica embevecida por idiossincrasias culturais, políticas, sociais e ideológicas, já que "o regime democrático não se reduz a uma característica única, mas sim a articulação e o equilíbrio entre vários princípios separados” (Todorov, 2012, p. 193), e que, portanto, os “diferentes graus de democracia dependem de várias razões vinculadas à história e a sociedade de qualquer país” (Bobbio, 2003, p. 243).

Independentemente de sua relativização conceitual, por traduzir uma ideia a que falta unanimidade de conceito ${ }^{1}$,não impediu que o século XX fosse marcado por uma emergência 
da democracia, na visão de Amartya Sen (apud Avritzer \& Santos, 2003, p. 01), ao vivencia-la como um desejo coletivo irrefreável que se espalha "verbalmente através do globo [...] colecionando amigos e inimigos e alistando forças de modo a lhe garantir uma preponderância provisória nos cenários em que ela conquista ascendência" (Dunn, 2014, p. 189).

Em leitura ao percurso da democracia no século XX, Avritzer e Santos (2003, p. 01) afirmam que esse período histórico "foi efetivamente um século de intensa disputa em torno da questão democrática”, ora com debates sobre a desejabilidade da democracia, ora com discussões em torno de suas condições estruturais.

Quando Burawoy (2015) incita seus pares à construção de uma sociologia global que possa atender a questão da temática da desigualdade na atualidade ${ }^{2}$, menciona como pano de fundo a sua reflexão uma onda de movimentos sociais entre os anos de 2010-2014, com destaque a revolução de 25 de janeiro no Egito, que levou a queda de Hosni Mubarak, as revoluções na Líbia, Iêmen, no Bahrein, na Síria, o desastre ambiental no Japão, o do Indignados em Portugal, e o 15 de março na Espanha, o Golden Dawn, na Grécia, dentre outros, que guardam entre si uma mútua influência, já que está globalmente conectada.

Embora se apresentem com dinâmicas distintas, em vista de seus panoramas nacionais, carregam consigo um simbolismo: as concentrações ocorriam em espaços públicos centrais de suas cidades -notadamente as praças ${ }^{3}$-, o que indicava um espírito democrático em suas exortações, numa horizontalização de suas energias, com a dissolução de qualquer estrutura hierarquizada de poder, e que apontam em direção a "uma consciência diferente, uma noção de possibilidade diversa, uma crítica do existente como sendo não natural e tampouco inevitável e, com ela, uma nova política informal” (Burawoy, 2015, p. 158).

Por sua vez, Todorov (2012) registra que a ideia de democracia no início do século XXI passa a reluzir com mais intensidade em redutos outrora improváveis, como a China, Cuba, os países do leste europeu e, mais recentemente, os 
4. "Durante o inverno 2010-2011, o mundo assistiu a um evento imprevisto: em vários países árabes do Oriente Médio Próximo e do Oriente Médio, a população expressou espontaneamente sua condenação aos ditadores que a governam e seu desejo de se instaurarse em suas próprias pátrias um regime democrático [...] seja qual for o destino político de todos esses países, já podemos considerar como estabelecido que o modelo democrático exerce hoje uma grande atração fora do mundo ocidental que o viu nascer. $O$ fato é tanto mais impressionante quando vemos esse mesmo modelo, já em ação na

América Latina ou Sudeste Asiático, desempenhar um papel -mais limitado, é verdade, pois o adversário é potente- na China; os dissidentes chineses também pregam a democracia [...] Esses movimentos, que foram chamados, talvez impropriamente, de 'revoluções árabes', já trouxeram um primeiro resultado: mostraram que a população de vários países não europeus compartilha as aspirações dos povos europeus: nem a civilização árabe nem a religião muçulmana impedem de sentir atração pela democracia" (Todorov, 2012, pp. 189-190).

5. "Combatê-las e neutralizá-las é tanto mais difícil quanto mais elas invocam o espirito democrático e possuem, assim, as aparências de legitimidade" (Todorov, 2012, p. 14). países muçulmanos do Oriente Médio, que passaram a bradar palavras de vigor aos seus princípios, e os seus compromissos com a promoção das liberdades humanas e com o fomento de um ambiente de bem-estar social ${ }^{4}$.

Sobre o triunfo desse sentimento democrático, em comparação das demais formas de organização do espaço social, como um sinal claro de sua força natural, ao menos como um modelo que inclusive passa a exercer grande atração para além de seu berço ocidental, afirma Todorov (2012, p. 14) que "nenhum modelo de sociedade diferente do regime democrático se apresenta hoje como seu rival; muito pelo contrário, vê-se uma aspiração à democracia se manifestar quase por toda a parte onde ela antes estava ausente".

No entanto, conforme observa Santos (2013), se a democracia como ideia "é hoje menos questionada do que nunca, todos os seus conceitos satélites têm vindo a ser questionados e declarados em crise: a patologia da participação, sob a forma de conformismo, do abstencionismo e da apatia política [...]" (Santos, 2013, p. 29).

Desse modo, a novidade dos novos tempos é que a democracia só sucumbirá por seus próprios inimigos íntimos, na medida em que engendra em si às forças que a ameaçam ${ }^{5}$ e, portanto, um olhar sobre a natureza dos fenômenos que descrevem esse novo tempo e a sua influência sobre as relações humanas na atualidade é indispensável para a compreensão de alguns dos perigos que a democracia promove contra si. 


\section{As sociedades pós-guerras e o espírito do novo capitalismo, por Richard Sennett}

Richard Sennett (2006), em estudo sobre as sociedades pós-guerras mundial, procura revelar o espírito que a emoldura, e identifica que a alma dessas comunidades contemporâneas é embevecida pela cultura do que se convencionou chamar de um novo capitalismo, e diz-nos que a separar o novo do velho talvez o sinal que melhor traduzisse o contraste seja o papel da globalização, que forja um cenário de redes interligadas em uma economia global, com inovações na área da tecnologia de comunicações e transportes, com a presença das grandes corporações multinacionais, que passam a assumir compromissos que não se resumem a identidade nacional, e que acabam por mudar a forma dos relacionamentos humanos.

O velho capitalismo, segundo Sennett (2006), seria o capitalismo social pensado por Max Weber ${ }^{6}$, de inspiração militarista e de estrutura piramidal, e cujos elementos de identificação centravam-se na paz e na segurança social (prevenção à revolução), evitando-se o tumulto e a revolta, mas que assegurava a estabilidade, e igualmente o lucro.

A racionalização da vida é a marca indelével do capitalismo social, em um processo de formação pessoal que prepara o jovem para o encaminhamento de toda uma vida, com a possibilidade de planejamento (como carreiras e posses, p. ex.) como seu elemento vital, e que revelava a sua preocupação com a questão da administração do tempo, de longo prazo, cumulativo e previsível.

Ao dispor a estrutura na forma de uma pirâmide, planeja-se simbolizar que a cadeia de funções teria uma ordem impressa, uma rede de comando que fluía de cima para baixo, em que cada posto, cada parte teria uma função pré-definida, e que cabia a cada um a função que lhe fosse própria e, portanto, realizadora de justiça social, uma vez que abrigaria em seu seio o maior número de pessoas,

6. Uma estrutura que substituiria a fluidez do capitalismo primitivo, pela estabilidade do capitalismo social, assegurando a longevidade dos negócios e aumentando o número de empregados, estrutura na qual, "assim como nos exércitos, todos tinham seu lugar e cada lugar a sua função definida" (Sennett, 2006, p. 27), e mediante a evocação de princípios típicos dos militares, como campanha de investimento, pensamento estratégico e análise de resultados, em que cada um compreendia a sua função e importância no empreendimento. 
7. Tal perspectiva, segundo Richard Sennett (2006) simbolizou uma época na formação do pensamento humano, espalhando-se por diversos setores da vida social, inclusive no ambiente das instituições públicas, e impregna-se na vida social de tal forma que talvez "os civis não se dessem conta de que estavam pensando como soldados" (2006, p. 29).

8. "A estabilidade parecia sinal de fraqueza, indicando no mercado que a empresa não era capaz de inovar, encontrar novas oportunidades ou gerir de alguma outra forma a mudança" (Sennett, 2006, p. 44). distribuídas as funções conforme suas aptidões e capacidades.

É justamente a definição prévia, fixas e estáticas de funções, e a possibilidade de participação plural de todos, conforme seu talento, o espirito de conforto que simbolizava o capitalismo social e, desse modo, havia um paradigma confortável sobre a vida e o futuro, representado na ideia de segurança e estabilidade, e é justamente nesse conforto paradigmático, que o tempo levaria a desmanchar no ar, pondo o homem na perspectiva de ficar isolado e à deriva, que se posiciona o cerne diferencial entre a cultura do novo e do velho capitalismo.

O modelo piramidal e militarizado do capitalismo social impactou e influenciou a cultura capitalista do século $\mathrm{XX}^{7}$,e deixa como maior legado, segundo Richard Sennett (2006) a forma de organização do tempo, por conferir estabilidade (fortalecendo a ordem de poder) e confiança (para entender que se fazia parte de um processo contínuo e com resultados efetivos) para as relações havidas dentro da estrutura militarizada do capitalismo social.

Mas como todo fenómeno social, o capitalismo social não se consolida como uma cultura permanente, sendo substituído em outro momento da história por novas formas de comportamento humano, pois motivados por novos valores e perspectivas. Expõe Sennett (2006) como motivos ao eclipse do capitalismo social, na segunda metade do século XX, a mudança na forma de gerenciamento empresarial, que passa a contar com a presença do investidor, que promove nas empresas a mudança do poder gerencial para o poder acionário.

A motivação não é mais a estabilidade e a segurança do processo $^{8}$, mas simplesmente o lucro, que há de ser auferido em curto prazo, para justificar o investimento e, para isso, abandonam a rigidez militar para absorver a capacidade de mudança e flexibilidades internas, de modo a revelar certo dinamismo, na expectativa de atrair sempre mais investimentos.

É a ideia do capital impaciente, em expressão cunhada por Bennett Harrison, (Sennett, 2006), em que a confiança 
não era mais traduzida na estabilidade das relações, mas na capacidade dinamismo, de mudança e, nesse cenário, as pessoas deveriam reinventar-se continuamente, ou pereceriam nos mercados?.

Desse modo, a mudança no processo capitalista é embalada pelo desenvolvimento de novas tecnologias de comunicação e transportes, o que simplifica a comunicação entre os diversos setores da sociedade e da própria empresa, e institui ainda à automação no processo de produção, com a dispensa de homens para a realização de tarefas rotineiras, com a inversão, portanto, da ideia da inclusão estimulada pelo capitalismo social, como mecanismo de justiça social.

Nesse novo cenário, o desenvolvimento linear é substituído por uma predisposição mental capaz de permitir a flexibilização ${ }^{10}$, inclusive com a possibilidade de realização de tarefas por pessoas estranhas a fisiologia da empresa (terceirização), na chamada dessedimentação institucional. Por outro lado, esse sequenciamento não linear, influencia na própria densidade da estrutura, que passa a ser de natureza volátil, ora a incluir, ora a se contrair, a medida que a empresa transita de uma função a outra (causalização).

Por esse conjunto de fatores -sequenciamento não linear, dessedimentação institucional e causalização, que constitui a espinha dorsal da nova arquitetura institucional-, impõe-se ao homem o desenvolvimento de outras capacidades, já que não mais se espera dele uma atitude passiva de conformismo, mas de própria pró-atividade, em situações tão ambíguas como a que oferece esse cenário de intensa flexibilidade organizacional.

Outro fator decorrente da nova página do capitalismo é a questão do sentido de autoridade que se torna essencialmente impessoal e, por isso, apresentase com baixa identificação, com a falta de confiança dos subordinados em relação aos postos de comando. Sobrevive o controle, mas com menos autoridade. 
E, nesse sentido, colocam-se os homens em posição de insegurança e ansiedade, brotando desse sentimento o que o Sennett (2006) denomina de déficit sociais, oriundos desse desapego à burocracia social, proveniente da eliminação das jaulas de ferro, que são a) o baixo nível de lealdade institucional, b) a diminuição da confiança informal, e c) o enfraquecimento do conhecimento institucional, e um claro empobrecimento do capital social, descrito no grau de envolvimento de uma pessoa nas diversas redes que formatam uma organização social.

\section{A crise da liberdade como um inimigo íntimo à democracia}

Dentro da perspectiva desse novo capitalismo referido por Sennett (2006), inaugura-se uma nova página na história das relações humanas, uma nova página que libertaria as pessoas da jaula de ferro da burocracia social. Mas a que liberdade esse novo espirito capitalista seria capaz de forjar?

Han (2012) define essa sociedade pós-moderna capitalista como sociedade da transparência, e descreve-a como planeadas em uma estrutura de informação em velocidade e de exposição em grau superlativo, o que colocaria o homem num ambiente de liberdade aparente, na medida em que a sensação de liberdade fomentada é uma astúcia do próprio sistema, já que na livre concorrência, o que de fato é livre é o capital, o qual para se reproduzir explora a liberdade do indivíduo.

O tempo do império do capital, para relembrar Sennett (2006), vivido em um dinamismo incessante e de flexibilidades, em um tempo que produz uma paisagem de intensa competitividade, de fluidez incessante de informações, e de exposição contínua; que fomenta a ideia de liberdade como uma inteligente forma de coação, pois estimula que o próprio indivíduo se explore a si mesmo, para poder alcançar os objetivos propostos, de sucesso e de bem-aventurança. Com isso, nesse tempo, o capitalismo envolve as pessoas 
no seu próprio funcionamento, "visto serem necessárias à produção e ao desenvolvimento dos mercados, onde a liberdade de ação e de empreender imbrica a própria estrutura do capitalismo" (Ferreira, 2014, p. 236).

Desse modo, a inteligência e sutileza desse sistema é que, em vez de subjugar o homem ao seu império, seduz, motiva e otimiza as suas ações, consentindo-as e satisfazendo-as, em uma ilusão que, em vez de torná-los submissos, torna-os dependentes. $\mathrm{E}$ assim procede sem que se apresente qualquer resistência, já que pelo fato do homem explorar a si próprio o fracasso não pode ser atribuído ao outro, o que inibe o oferecimento de resistência ao sistema, senão cobrar de si os resultados do insucesso de seu empreendimento, e "esta auto-agressão (sic) transforma o explorado, não em revolucionário, mas em depressivo" (Han, 2014, p. 16).

Em sua leitura sobre esse novo tempo, Bauman (2001) define-o como o tempo da modernidade liquida, e vale-se da metáfora da liquidez para descrevê-la como uma época de volatilidade e incertezas; de um tempo de referenciais morais fragmentadas; um espaço que se rende ao consumo e a artificialidade das relações entre pessoas e com as instituições; de se apreciar o que é descartável e belo; o que é pueril e fluído. Um cenário que leva o homem ao estado de conformidade total, um espectador cômodo de sua própria vida. Que vê e participa do mundo no anonimato da vida digital. Um vigilante passivo e integrado na rotina incessante das informações.

Para Debord (2003, p. 14) é o tempo das sociedades do espetáculo, "em que o espetáculo não é um conjunto de imagens, mas uma relação social entre pessoas, mediatizadas por imagens". O tempo espetacular como o tempo de consumo das imagens, "em que tudo o que era diretamente vivido se esvai na fumaça da representação" (Debord, 2003, p. 121).

O tempo do novo capitalismo descobre a psique 
11. "A forma de poder do regime neoliberal constitui a realidade não vista pela análise foucauldiana de poder. Foucault não vê nem que o regime neoliberal de dominação acapara totalmente a tecnologia do eu, nem que a otimização de si permanente, enquanto técnica do eu neoliberal, não é outra coisa senão uma forma de dominação e de exploração eficaz. [...] A técnica de poder do regime neoliberal adota uma forma subtil. Não se apodera diretamente do indivíduo. Pelo contrário, procura assegurar que o indivíduo aja de tal modo que reproduza por si próprio a estrutura de dominação que interpreta como liberdade. A otimização de si e a submissão, a liberdade e a exploração coincidem aqui plenamente" (Han, 2014, pp. 37-38).

12. "A técnica ortopédica do poder disciplinar é demasiado grosseira para penetrar nas camadas profundas da psique e nos seus anseios ocultos, as suas necessidades e os seus desejos, e acabar por apoderar-se delas" (Han, 2014, p. 30).

13. "O regime disciplinar, segundo Deleuze, organiza-se como um 'corpo'. É um regime biopolítico. O regime neoliberal, pelo contrário, comporta-se como alma. Daí que a psicopolitica seja a sua forma de governo. Esta institui entre os indivíduos uma rivalidade interminável sob a forma de competição saudável, como uma motivação excelente'. A motivação, o projeto, a competição, a otimização e a iniciativa são inerentes às técnicas de dominação psicopolítica como força produtiva, e ocorre pela razão de que não se ocupa mais com a produção dos objetos físicos, mas com a criação de produtos não físicos, imateriais. Desse modo, ao contrário do panoptismo de Foucault em que o dispositivo de controle domestica o corpo enquanto parte de uma biopolítica, que engendra a obediência a um sistema de normas, nas sociedades da informação, o panoptismo não é mais do corpo, mas sim da mente ${ }^{11}$, não é mais físico, mas sim digital, como uma espécie de psicopanoptismo ${ }^{12}$.

O espirito do novo capitalismo não se interessa mais somente do corpo, do biológico, do somático, do corporal. Ela apropria-se da alma ${ }^{13}$. O poder no neoliberalismo retira do homem a capacidade de plena compreensão do mundo que o cerca, pois que tudo passa a ser subterfugio do próprio sistema de dominação, que estimula o homem servir-se de si próprio, em nome e em razão dos objetivos do capital.

Inserto nessa "miragem essencial do neocapitalismo", segundo Santos (2013), retira-se do homem a condição de percepção das próprias injustiças e irracionalidades dessa sociedade capitalista, e com isso propor "uma sociedade totalmente distinta e melhor que esta” (Santos, 2013, p. 151).

Essa falta de protagonismo do homem, tolhido em sua autonomia, e na sua capacidade de percepção dos fatos e do mundo, enaltece o que Santos (1998) batiza de crise do contrato social da modernidade, cuja legitimação se estabelece pela tensão existente entre inclusão e exclusão e, como consequência, verifica-se a perda de sentido e de atitudes proativas na luta pelo bem comum e por alternativas de bem comum, como sendo igualmente uma crise do pensamento estratégico de emancipação, ao mencionar que "à medida que a trajetória da modernidade se intensificou com a trajetória do capitalismo, o pilar da regulação veio a fortalecer-se à custa do pilar da emancipação num processo histórico não linear e contraditório” (Santos, 2013, p. 188).

A confusão da sociedade civil e do mercado em um único espaço ilude-nos em nome da liberdade, e a 
ideia de um ambiente livre é sempre tentadora, pois encaminha-nos na percepção de que somos nós os protagonistas de nossas próprias escolhas, e a possibilidade de fazê-las, direta e pessoalmente, nos torna mais vivo, já que em nós pulsaria a própria essência da vida.

E a transparência, uma ordem artificial, que rejeita a ambivalência, e em que tudo há de ser claro e límpido (Bauman, 1991), e por isso tão aclamada pela contemporaneidade, antes de reafirmar a autonomia do homem em relação aos fatos da vida, retirar-lhe a capacidade cognitiva, com a uniformização de práticas, atitudes e pensamentos, instituindo um "inferno dos iguais" (Han, 2012, p. 12), devido à diminuição da capacidade humana para interagir ativamente com o universo que a cerca.

Imerso em tal cenário, não seria errôneo pensar que, sempre que nas sociedades de consumo o homem tem preferência pela participação no mercado em vez de participar na vida política, o consumidor ocupará o espaço do cidadão ${ }^{14}$, em que "a natureza do consumo metamorfoseia-se" em um "idealismo objectistico", na definição de Santos, (2013, p. 209), e com isso constrói um subjetivismo narcisista, autista e cultual dos objetos ${ }^{15}$, na medida em que a naturalização do mercado estimula um olhar passivo, e por vezes, conivente do homem com a estrutura posta.

Para Debord (2003) nas sociedades do espetáculo, o espectador é um simple alienado diante do objeto contemplado, e que estimula em si uma aceitação passiva diante da mensagem emitida pela imagem e, desse modo, "quando mais ele contempla, menos vive; quanto mais aceita reconhecer-se nas imagens dominantes da necessidade, menos ele compreende a sua própria existência e o seu próprio desejo" (Debord, 2003, p. 26), e que, por isso, "o espetáculo na sociedade representa concretamente uma fabricação de alienação" (Debord, 2003, p. 26). do regime neoliberal"

(Han, 2014, p. 28).

14. "O neoliberalismo transforma o cidadão em consumidor. A liberdade

do cidadão cede ante

a passividade do

consumidor. O votante, enquanto consumidor, não tem interesse real pela política, pela configuração ativa da comunidade. Não está disposto nem capacitado para a ação política comum. Limita-se a reagir de forma passiva à política, protestando e queixando-se, do mesmo modo que o consumidor perante as mercadorias

e os serviços que

lhe desagradam"

(Han, 2014, p. 19).

15. "A aspiração de autonomia, criatividade $\mathrm{e}$ reflexividade é transmutada em privatismo,

dessocialização e narcisismo, os quais, acoplados à vertigem produtivista, servem para integrar, como nunca, os indivíduos na compulsão consumista.

Tal integração, longe de significar uma cedência materialista, é vivida como expressão de um novo idealismo, um idealismo objectistico" (Santos, 2013, pp. 298-299). 


\section{Democracia sem participação não é democracia}

16. "Os gregos, de cuja língua surgiu a palavra, a distinguiam de outras formas de governo: aquela na qual o poder pertence a um só, 'monarquia' em sentido positivo, 'tirania' em sentido negativo; e aquela em que o poder pertence a pouco, 'aristocracia' em sentido positivo, 'oligarquia' em sentido negativo" (Bobbio, 2003, p. 235).

17. "A partir dessa diferença entre dois princípios opostos de legitimidade, a tradicional distinção das formas de governo, proveniente de um critério meramente quantitativo e, como tal, extrínseco-um, poucos, muitos-, é substituída por outra, que se tornou predominante, entre democracia e autocracia. Neste caso, a forma de governo democrática, seja direta ou indireta, se opõe a todas as demais na medida em que é a única na qual o poder se transmite de baixo para cima" (Bobbio, 2003, p. 236).
Diante desse contexto, como não se identificar com a advertência feita por Todorov (2012) ao revelar a sua preocupação sobre o estágio da democracia nos tempos de hoje, diagnosticando-a como doente de seu próprio descomedimento. Nesse campo de reflexão, na sua visão de democracia, não sofreria ela mais da ameaça de nenhum inimigo que lhe seja exterior, mas que a sua fraqueza repousaria em suas próprias estruturas, sempre que um dos pilares que lhe dá sustentáculo enfraqueça, a tal ponto que ameaça ruir em uma implosão catastrófica.

E das estruturas que edificariam um cenário democrático, Todorov (2012) anuncia como seus pilares a ideia de liberdade individual e de progresso, na medida em que "toda a democracia implica a ideia de um melhoramento possível da ordem social, de um aperfeiçoamento graças aos esforços da vontade coletiva" (Todorov, 2012, p. 17) e que essa vontade não seja submetida "aos efeitos de uma emoção passageira ou de uma manipulação hábil da opinião pública", mas sim "deve manter-se conforme aos princípios definidos após uma reflexão madura” (Todorov, 2012, p. 18).

Mesmo enevoada conceitualmente, a democracia sempre teve a sua compreensão associada à capacidade de participação do povo (demos) nas tomadas de decisão, isto porque, indica ser ela "o resultado de um acordo livre entre indivíduos inteligentes" (Bobbio, 2003, p. 254). Portanto, comunga com a compreensão de que o poder existente em uma dada sociedade política haveria de ser exercício pelo próprio povo (ou sem seu nome), pois a ele pertenceria a sua titularidade, e em seu interesse deveria ser efetivamente exercido ${ }^{16}$.

A democracia pode ser descrita como um regime onde o poder político é legitimado pelo povo ${ }^{17}$, e cujas decisões são guiadas em prestígio às liberdades humanas e, desse modo, por essa perspectiva deve-se pensar a democracia 
não apenas na ideia de quem exerce o poder, ou em nome de quem esse poder é exercido, mas, principalmente, nas formas de participação do homem nos assuntos de interesse geral, com a criação de instrumentos que permitem sua efetiva contribuição à formação da vontade coletiva que irá reger a vida em sociedade.

Quando se verifica esse aspecto do ideário democrático da atualidade, deparamo-nos com o fato de que o grau de participação efetiva do cidadão nos processos decisórios nas democracias modernas é cada dia mais diminuto, reduzido unicamente ao sufrágio, sendo que, "o sufrágio, que hoje é considerado o fato mais relevante de uma democracia, é o voto dado não para decidir, mas sim para eleger quem deverá decidir" (Bobbio, 2003, p. 245).

A naturalização da matriz representativa da democracia, de inspiração liberal, em que "a cidadania abrange exclusivamente a cidadania civil e política e o seu exercício reside exclusivamente no voto" (Santos, 2013, p. 190) conduz à passividade política dos cidadãos.

Por sua vez, Rancière (2014, p. 43) diz-nos que "a vida democrática torna-se a vida apolítica do consumidor indiferente de mercadorias", e que o poder de governar limita-se a servir de "fiador dos 'pequenos prazeres' que pagam nossa grande aflição de órfãos condenados a vagar pelo império do vazio, o que significa indiferentemente o reino da democracia, do indivíduo e do consumo" (Rancière, 2014, p. 46).

Para Rancière (2014) é preciso transcender a identificação da democracia como um mero estado de sociedade ${ }^{18}$, como um reino do indivíduo igualitário, que se porta diante de diferentes fenômenos como um "consumidor democrático embriagado de igualdade"19, e que se identifica "conforme o humor e as necessidades da causa, com o assalariado reivindicativo, com o desempregado que ocupa os escritórios da Agencia Nacional para o Emprego ou com o imigrante ilegal
18. A equação democracia $=$ ilimitação $=$ sociedade que sustenta a denúncia dos 'crimes' da democracia pressupõe, portanto, uma operação tripla: em primeiro lugar, reduzir a democracia a uma forma de sociedade; em segundo lugar, identificar essa forma de sociedade com o reino do indivíduo igualitário, subsumido nesse conceito todo o tipo de propriedades distintas, desde o grande consumo até as reivindicações dos direitos das minorias, passando pelas lutas sindicais; e, em terceiro

lugar, atribuir à 'sociedade individualista de massa', assim identificada com a democracia, a busca de um crescimento indefinido, inerente à lógica da economia capitalista" (Rancière, 2014, p. 31).

19. No Brasil, o aumento no preço das passagens de ônibus deu início as manifestações de 2013, e que tiveram seu estopim após uma forte repressão policial contra os manifestantes de São Paulo, assim, o movimento ganhou proporções maiores, com repercussão em todo o país, com gritos em uníssono de "não" a situações que ocorriam no país eclodiram de várias capitais. Caminhadas em busca de explicações sobre a Copa do Mundo no Brasil, sobre os gastos públicos, sobre a corrupção, sobre os serviços públicos de má qualidade foram algumas das pautas da reivindicação. Os cidadãos queriam soluções, respostas às perguntas que se encontravam soterradas. Inclusive, é interessante ressaltar que tais reivindicações não eram 
específicas, pelo contrário, eram múltiplas as

demandas que a população exigia num único protesto, o que talvez demonstre a natureza e a forma dessas manifestações como

daquelas inseridas em um corpo de reivindicações difusas, e próprias de um consumidor insatisfeito com os serviços que lhe são oferecidos.

20. Na mesma perspectiva é a observação de ByungChul Han quando diz: "A transparência que se exige dos políticos é tudo menos uma reivindicação política. Não se exige transparência perante os processos políticos de decisão, pelos quais nenhum consumidor se interessa. $\mathrm{O}$ imperativo da transparência serve sobretudo para expor os políticos, para os desmascarar, para os transformar em objeto de escândalo. A reivindicação da transparência pressupõe a posição de um espectador que não se escandaliza.

Não é a reivindicação de um cidadão com iniciativa, mas a de um espectador passivo. A participação tem lugar sob a forma de reclamação e de queixa. A sociedade da transparência, habitada por espectadores e consumidores, funda uma democracia de espectadores" (2014, p. 20).

21.“[...] Hoje, os Estados democráticos são governados, embora em diferente medida, por meio de democracias representativas, só em alguns casos combinados com elementos de democracia direta, como o referendo. O mecanismo da representação é a tal ponto constitutivo da democracia moderna que, quando se diz que os Estados Unidos confinado nas zonas de espera dos aeroportos" (Rancière, 2014, pp. 41-42) ${ }^{20}$.

Ver a democracia com esta fisionomia é compreendê-la como um espetáculo, que fomenta no espectador uma atitude apática em relação aos temas de interesse comum, pois que está mais interessado em realizar seus desejos privados e egoístas, o que acaba por ensejar a "identificação solidamente estabelecida entre o homem democrático e o indivíduo consumidor" (Rancière, 2014, p. 36).

É a instituição de uma democracia de sufrágios, ou uma democracia de espectadores, em que no espirito e no ambiente que anima os regimes democráticos hodiernamente, o poder transforma o homem, não mais em submissos, mas em dependentes.

Nessas democracias de sufrágios submergimo-nos à falsa compreensão de que a democracia se resume no comparecimento periódico às urnas, para escolha de nossos representantes ${ }^{21}$. Enquanto que nas democracias de espectadores vivemos uma alienação estimulada, que nos põe em cômoda posição de observadores, diante de um enredo que nos passa a vista, a nos contar uma história em que somos o protagonista.

Para Santos (2013), a construção de uma nova teoria da democracia parte da "formulação de critérios democráticos de participação política que não confinem esta ao acto de votar" (Santos, 2013, p. 225), o que necessariamente implica na ampliação do próprio campo político, que não mais poder ficar restrito ao espaço da cidadania, "como o espaço político segundo a teoria liberal" (Santos, 2013, p. 226) 22 .

Uma nova gramática da democracia perpassa pela intensificação de um discurso argumentativo que agregue em si o estimulo à participação, com o incentivo a outras formas de manifestações democráticas para além da representativa ${ }^{23}$, e até mesmo para além dos tradicionais movimentos sociais. Mas como uma atitude que principia na consciência de que a responsabilidade participativa é um compromisso a ser 
vivido desde as mais singulares interações sociais (que envolvam pessoas e pessoas e coisas, como a preservação de bens públicos e à própria natureza, p. ex.) até as mais complexas questões sociais ${ }^{24}$.

A manutenção desse status quo ofende a dignidade democrática, centrada na consciência plena das liberdades humanas, e essa se manifesta não apenas no exercício dos clássicos direitos de liberdade, mas principalmente no estímulo ao desenvolvimento da aptidão natural do ser humano em participar mais ativamente de seu próprio destino ${ }^{25}$, do de toda a coletividade com a qual convive, e do ambiente social e natural no qual habita, que nada mais seria senão uma extensão de sua compreensão como pessoa humana.

Os exemplos mencionados no início desse texto sinalizam que aquela emergência da democracia ainda persiste, e é, portanto, preciso saber ouvir os sinais, e elas já ecoam com força e vigor nas ágoras modernas (praças, ruas, universidades, redes sociais, etc.), ciente de que a democracia é um projeto em permanente desenvolvimento ${ }^{26}$, que não nascera com a pretensão da perfeição, e nem da construção de uma nova sociedade, "cujos elementos seriam formados no próprio seio da sociedade atual” (Rancière, 2014, p. 121), mas que precisa ser descoberta a partir dos fins que pretende alcançar, alimentados pela crença na capacidade futura do projeto democrático a partir da participação ativa e plena dos indivíduos.

\section{Considerações finais}

Oriundo de poder (krátos) legitimado pelo povo (demos), a democracia é o cenário descrito como a forma de governo no qual as decisões políticas deverão ser guiadas pelo sentimento de prestígio às liberdades humanas e, quando se faz um paralelo entre as diferentes manifestações de democracia ao longo da história, Bobbio (2003, p. 235), ou a Itália são países democráticos, subentendese que a democracia neles existente é representativa"

(Bobbio, 2003, p. 235).

22. "A nova teoria da democracia -que também poderíamos designar por teoria democrática pósmoderna para significar a sua ruptura com a teoria democrática liberal- tem, pois, por objetivo alargar e aprofundar o campo político em todos os

espaços estruturais de interação social” (Santos,

2013, p. 231).

23. É a ideia de demodiversidade, entendida como a "coexistência pacífica ou conflitual de diferentes modelos e práticas democráticas" (Avritzer \& Santos, 2003, p. 22).

24. "A força da globalização contrahegemônica no domínio da ampliação e do aprofundamento da democracia depende em boa medida da ampliação

e aprofundamento de redes nacionais, regionais, continentais ou globais de práticas locais" (Avritzer \&

Santos, 2003, p. 24).

25. Consolidação de um processo democrático implica, também, um profundo investimento na educação dos cidadãos, uma educação que proporcione a cada cidadão condições de compreender o contexto social em que vive e, consequentemente, garanta sua liberdade de escolha. Subjacente a isso, pressupõe-se um contexto de igualdade de oportunidades, a fim de que cada um possa desenvolver seus potenciais e estar no espaço público, onde ocorrem 
as decisões políticas, com a mesma dignidade que os demais participantes; caso contrário, o processo de escolha e de deliberação estará viciado, pois alguns cidadãos terão mais poder para convencer e para impor seus interesses do que outros, fator que desequilibra por completo a balança que deve reger o processo democrático (Auad et al., 2004, p. 5).

26. “A democracia não é nem a forma de governo que permite a oligarquia reinar em nome do povo nem a forma de poder da mercadoria. Ela é a ação que arranca continuamente dos governos oligárquicos o monopólio da vida pública e da riqueza a onipotência sobre a vida. Ela é a potência que, hoje mais do que nunca, Wdeve lutar contra a confusão desses poderes em uma única e mesma lei da dominação" (Rancière, 2014, p. 121).

27. Em uma democracia, é importante "[...] que suas instituições não só reconhecem formalmente todos os seus cidadãos como iguais, mas também que realmente distribuem o poder imparcialmente até mesmo através de suas classes, conferindo a cada um uma parcela substancialmente igual na prática para todos os propósitos publicamente pertinentes" (Dunn, 2014, p. 191).

\section{Em A grande} transformação, de 1944, o Karl Polanyi cunha o conceito de mercadorias fictícias para identificar um conjunto de bens imateriais a qual se atribuiria valor mercantil para que pudessem serem eles passíveis de troca, como o simplificaria a distinção ao dizer que "a democracia dos antigos se distingue da dos modernos pela maneira como o povo exerce o poder: diretamente, na praça ou ágora entre os gregos, e indiretamente, por meio de representantes, nos Estados modernos".

Todavia, para os objetivos da linha argumentativa exposta neste ensaio, muito mais importante que a distinção clássica acima referida, ou qualquer outra porventura identificada na doutrina especializada, é a compreensão da ideia de que a democracia inspira-se no postulado do poder legitimado, como um poder ascendente, legitimado pela vontade do homem (consentimento).

Dessa forma, a democracia, como princípio de convivência humana deve ser a promotora de um sistema de igualdade plena para todos os seus cidadãos, em que o mais amplo gozo das liberdades humanas há de ser estimulada. Portanto, é preciso pensar que a democracia não se baseia apenas na ideia de quem exerce o poder, ou em nome de quem esse poder é exercido, mas, principalmente, nas formas de participação do homem nos assuntos de interesse geral, fomentando a criação de instrumentos que permitem sua efetiva contribuição à formação da vontade coletiva que irá reger a vida em sociedade ${ }^{27}$.

De modo que não feneça a aspiração universal pela democracia, é preciso que os fins democráticos sejam consentâneos com os meios (instrumentos) democráticos, e não o contrário, em uma atitude sacrificial aos valores democráticos, com a suposta justificativa de se "salvar a democracia", como o são os ataques permanentes à liberdade pela lógica do espetáculo e do consumo, em que a própria liberdade é vista como uma mercadoria (fictícia, na descrição de Karl Polanyi ${ }^{28}$, e, portanto, sujeitas ao império do mercado e do capital neoliberal.

Para esse fim, comungamos com Santos (2013) na necessidade de redefinir o conceito de cidadania, como uma ideia emancipatória, a partir da construção de um 
novo senso comum, em que essa nova cidadania se constitua e se desenvolva tanto na "obrigação política vertical entre os cidadãos e o Estado como na obrigação política horizontal entre os cidadãos. Com isto, revaloriza-se o princípio da comunidade e, com ele, a ideia de igualdade sem mesmidade, a ideia de autonomia e a ideia de solidariedade" (Santos, 2013, p. 233).

Uma cidadania emancipatória é uma cidadania que atende a um olhar de mundo até então excluído, e que, conforme Santos (2003) seria construído pelo estímulo a uma epistemologia adequada, alicerçada na ideia de justiça social a partir de uma justiça cognitiva, que reconhece o valor do conhecimento emancipação (em que a ignorância é concebida como colonialismo e o saber como solidariedade) em detrimento do conhecimento regulação (em que a ignorância é concebida com um caos e o saber como ordem $)^{29}$, a que caracterizou de pensamento pós-abissal inserido em uma Epistemologia do Sul, na medida em que reconheceria a diversidade do mundo como algo inesgotável, e não limitada unicamente à compreensão ocidental do mundo, e, no nosso caso, de democracia liberal representativa, pois que "a negação de uma parte da humanidade é sacrificial, na medida em que constitui a condição para a outra parte da humanidade se afirmar enquanto universal” (Santos, 2007, p. 10).

Por óbvio que não se está a promover uma inquisição do regime representativo de democracia, que ainda tem seu valor e sua importância, mas um convite a repensar a sua estrutura atual, agonizante em suas próprias limitações, abrindo-se espaço para a criação de um ambiente dialógico, que estimulem a consciência para uma maior participação do povo nas tomadas de decisões, compartilhando com os representantes eleitos a responsabilidade com os destinos de sua nação, uma virtude que há de ser permanentemente estimulada, como uma ínsita condição de sua soberana liberdade. trabalho, a terra,

o dinheiro e o

conhecimento, e no nosso caso, a liberdade.

29. “À medida em que a modernidade ocidental, enquanto paradigma sócio-cultural, reduziu as possibilidade de emancipação à compatíveis com o capitalismo, o conhecimento-regulação adquiriu uma total preponderância sobre o conhecimentoemancipação e

neutralizou-o, convertendo a solidariedade numa forma de caos, e, portanto, de ignorância e o colonialismo numa forma de saber e, portanto, de ordem [...] Convertida em conhecimento uno e universal, a ciência moderna ocidental, ao mesmo tempo em que se constituiu em vibrante e inesgotável fonte de progresso tecnológico e desenvolvimento capitalista, arrasou, marginalizou ou descredibilitou todos os conhecimento não científicos que lhe eram alternativos, tanto no Norte como no Sul. Tenho designado este processo como epistemicídio (1998c: 208)" (2010, p. 143). 


\section{Referências bibliográficas}

Almeida, Rafael Alves de \& Almeida, Tânia (2014). Democracia deliberativa e construção do consenso. In Asensi, Felipe Dutra \& De Paula, Daniel Giotti (coords.). Tratado de Direito constitucional. 1a ed. Rio de Janeiro: Elsevier.

Aristóteles (2010). Política. 5a ed., 3ª reimp. São Paulo: Martin Clarin.

Avritzer, Leonardo \& Santos, Boaventura de Souza (2003). Para ampliar o cânone democrático. In http://www.eurozine.com /articles/article_2003-11-03-santospt.html.pdf.

Auad, Denise et al. (2004, jan.-jun.). Mecanismos de participação popular no Brasil: plebiscito, referendo e iniciativa popular. In Revista Brasileira de Direito Constitucional. No 3. Editora Método.

Bauman, Zygmunt (1991). Modernidade e ambivalência. Lisboa: Relógio D’Água.

Bauman, Zygmunt (2001). Modernidade líquida. Rio de Janeiro: Jorge Zahar.

Bobbio, Norberto (2003). O filósofo e a política: antologia. [Organização e apresentação, José Fernandez Santilán]. Rio de Janeiro: Contraponto.

Burawoy, Michael (2015). Encarando um mundo desigual. In: Revista do Programa de Pós-Graduação em Sociologia da USP, São Paulo. Vol. 22.1, pp. 142-181.

Debord, Guy (2003). A sociedade do espetáculo. In http://www.ebooksbrasil.org/ adobeebook/socespetaculo.pdf.

Dunn, John (2014). Democracia como espectro, sonho e realidade. In Asensi, Felipe Dutra \& De Paula, Daniel Giotti (coords.). Tratado de Direito constitucional. $1^{\text {a }}$ ed. Rio de Janeiro: Elsevier.

Ferreira, Antônio Casimiro (2014). Política e sociedade: teoria social em tempo de austeridade. Porto: Vida Económica.

Giannattasio, Arthur Roberto Capella (2014). Direitos e democracias: reflexos da democracia deliberativa. In Asensi, Felipe Dutra \& De Paula, Daniel Giotti (coords.). Tratado de Direito constitucional. $1^{\mathrm{a}}$ ed. Rio de Janeiro: Elsevier.

Han, Byung-Chul (2012). A sociedade da transparência. Lisboa: Relógio D’Agua.

Han, Byung-Chul (2014). Psicopolítica. Lisboa: Relógio D’Agua.

Rancière, Jacques (2014). O ódio à democracia. São Paulo: Boitempo.

Santos. Boaventura de Sousa (1998). Reinventar a democracia. Lisboa: Gadiva.

Santos, Boaventura de Sousa (2007, out.). Para além do pensamento abissal: das linhas 
globais a uma ecologia de saberes. In Revista Crítica de Ciências Sociais, 78, pp. 3-46.

Santos, Boaventura de Sousa (2010). A gramática do tempo para uma nova cultura política. Porto: Afrontamento.

Santos, Boaventura de Sousa (2013). Pela mão de Alice: o social e o político na pós-modernidade. Coimbra: Almedina.

Sennett, Richard (2006). A cultura do novo capitalismo. Rio de Janeiro: Record.

Todorov, Tzvetan (2012). Os inimigos íntimos da democracia. São Paulo: Companhia da Letras. 